\title{
Complement Measurement
}

National Cancer Institute

\section{Source}

National Cancer Institute. Complement Measurement. NCI Thesaurus. Code C80160.

The determination of the amount of complement present in a sample. 